\title{
UMA REFLEXÃO SOBRE PROCESSO DECISÓRIO NO GERENCIAMENTO DOS SERVIÇOS DE ENFERMAGEM
}

[A reflection on the power to decide process during the management of nursing]

\author{
Patrícia Maria Marcon* \\ Maria Ribeiro Lacerda** \\ Marineli Joaquim Meier***
}

RESUMO: Este artigo trata de uma reflexão sobre a Enfermagem enquanto prática profissional, exibindo seu processo de trabalho em três grandes áreas, definidas conforme algumas autoras, como o Cuidar, o Educar e o Gerenciar. Com enfoque nesta última, o objetivo deste estudo foi discutir a viabilidade de modelos de etapas do processo decisorial direcionados para aplicação na Enfermagem. Para o alcance desta proposta, fezse referência a três autores da área da administração, que apresentam modelos próprios. Após a compreensão e discussão dos referenciais teóricos, considerou-se que nem todos os modelos podem ser facilmente compreendidos e aplicados.

PALAVRAS-CHAVE: Gerenciamento em Enfermagem; Processo Decisório; Prática Profissional.

\section{INTRODUÇÃO}

A Enfermagem pode ser visualizada, conforme algumas autoras, como um processo de trabalho que envolve três áreas diferenciadas: 0 Cuidar, o Educar e o Gerenciar. Ao destacar o

*Enfermeira. Bolsista da CAPES/Mestrado do Programa de PósGraduação em Enfermagem da Universidade Federal do Paraná. Membro do Grupo de Estudo Multiprofissional em Saúde do Adulto GEMSA.

${ }^{* \star}$ Enfermeira. Doutora em Filososfia de Enfermagem. Professora do Programa de Pós-Graduação em Enfermagem da UFPR. Coordenadora da disciplina Enfermagem e sua Prática Profissional.

***Enfermeira. Doutora em Filosofia de Enfermagem. Professora do

Programa de Pós-Graduação em Enfermagem da UFPR. Membro do

Grupo de Estudo Multiprofissional em Saúde do Adulto - GEMSA. gerenciamento de Enfermagem enuncia-se que tais estudos são pouco explorados. Entretanto, essenciais à profissão, por subsidiar o enfermeiro a desenvolver recursos humanos, materiais e físicos às demais áreas. Neste trabalho a atenção foi direcionada ao processo de trabalho gerencial, aproximando-o com o processo de tomada de decisão.

O interesse por tal assunto surgiu desde a graduação, sendo incentivado pelo Curso de Especialização em Gestão dos Serviços de Enfermagem, que possibilitou vivenciar, questionar e imaginar soluções mais fundamentadas e adequadas para situações cotidianas da profissão. Tais situações envolvem e requerem conhecimentos específicos e científicos para uma conduta mais apropriada dos profissionais frente ao processo de tomada de decisão.

Marcon (2004), destaca que a maioria dos enfermeiros que ocupam cargos de gerência possui carências quanto a conhecimentos da área administrativa e, principalmente, sobre elementos que norteiam o processo de tomada de decisão. Mesquita (2002), considera que o enfermeiro gerencial além de suas inúmeras atividades, atua como 'elo de ligação' entre sua equipe de trabalho e as coordenações superiores. Desta forma tornase reconhecido como co-responsável na organização de trabalho, e como tal, é imprescindível que adquira conhecimentos básicos referentes à administração, legislação profissional, ética, bioética, entre outros, uma vez que estes são de grande aplicabilidade em processos decisórios. 
Nesse sentido a problemática do trabalho, centrou-se na ausência de reflexões sobre modelo de etapas do processo decisorial na Enfermagem. Considerando que as situações cotidianas do gerenciamento de enfermagem são complexas e envolvem diferenciados contextos e sujeitos, entende-se que há necessidade de uma reflexão fundamentada em conhecimentos científicos sobre as temáticas pertinentes ao processo de tomada de decisão ${ }^{1}$, na perspectiva de obter soluções e posicionamentos profissionais adequados e benéficos a todos os envolvidos.

Com esse entendimento apresenta-se, a seguir, uma explanação teórica sobre a Enfermagem, as três áreas do seu Processo de Trabalho, e o Processo de Tomada de Decisão. Assim, o enfoque se concentrará no Processo Decisório e alguns modelos de etapas de autores da área administrativa. Foram escolhidos tais autores por representarem épocas diferenciadas da administração. No entanto ressalta-se que existem diversos outros autores que também apresentam seus modelos de etapas próprios.

Após tal descrição será realizada uma discussão sobre estes, buscando direcioná-los para a aplicação na Enfermagem.

\section{A PRÁTICA DE ENFERMAGEM E O PROCESSO DECISÓRIO}

A Enfermagem enquanto profissão surgiu da necessidade do ser humano em obter assistência à saúde, cujo produto de seu trabalho é classificado como serviço, em função do seu resultado não ser caracteristicamente concreto, - o cuidado ao ser humano - no entanto, de essencial importância à vida e à assistência de saúde.

Nesse sentido pode-se compreender a enfermagem, utilizando o conceito de Rodrigues et al. (2003, p.26), sob a óptica de Capella (1998):

É uma prática social cooperativa,que se dirige para o desenvolvimento de ações assistenciais, administrativas e educativas, exercida por diversas categorias profissionais, hierarquizadas por complexidade de concepção e execução, exigindose além de conhecimento cientifico, o

${ }^{1}$ Neste trabalho os termos: Processo de Tomada de Decisão, Processo Decisório e Processo Decisorial serão utilizados como sinônimos. estabelecimento de relações profissionais e interpessoais. Apresenta como atividade básica assistir o individuo; também considerada institucionalizada, por ser desenvolvida, majoritariamente, em instituições de saúde, públicas ou privadas.

Essas concepções permitem ampliar o entendimento da Enfermagem enquanto prática profissional. Nesse sentido, para compreender tal processo de trabalho, é necessário primeiramente situá-lo no contexto histórico-social, destacando a sua inserção na instituição e os caminhos de trabalho desenvolvidos.

Tratando desse tema, Leopardi; Gelbecke e Ramos (2001), acordaram que a enfermagem possui um processo de trabalho complexo e, apresentam uma combinação de três ações básicas não dissociadas, ou seja, a educação, o cuidado e a gerência dos serviços de enfermagem. As autoras ao afirmarem que as três áreas direcionam-se para uma mesma finalidade: cuidado à necessidade do ser humano, declaram um mesmo grau de importância entre elas, referindo que, na maioria das vezes, desenvolvemse de forma interligada.

Tal qual as autoras, acredita-se em um processo de trabalho geral da Enfermagem, que ocorre de forma indissociada apesar de possuir três áreas diferenciadas: Cuidar, Educar e Gerenciar. O Processo de Trabalho Cuidar é o trabalho identificador da profissão, no qual a atuação da enfermagem tem como finalidade atender diretamente as necessidades relacionadas à saúde do ser vivo. O Processo de Trabalho Educar é dirigido para sensibilizar a conscientização de assuntos de saúde, individual e coletivamente. Este é diferenciado por considerar e respeitar crenças, hábitos, valores e conhecimentos dos envolvidos. Assim, salienta-se a comunicação como uma ferramenta extremamente importante que deve ser planejada, conforme os indivíduos a que se destina - objeto de trabalho - para desenvolver o ensino. $O$ Processo de Trabalho Gerencial é privativo do Enfermeiro, caracterizando-se como atividade provedora de recursos humanos, físicos e materiais no desenvolvimento do cuidado e/ou da educação. As autoras complementam, que o objeto de trabalho do gerenciamento é a organização em si.

Frente às considerações anteriores, percebese que tais ações complementam-se para resultar na finalidade da profissão. Desse modo, 
destaca-se que o enfermeiro assistencial, além de suas atividades voltadas diretamente ao cuidado do cliente, educa e gerencia durante o desenvolver de seu processo de trabalho. $O$ educador, também desenvolve o gerenciamento e a assistência ${ }^{2} \mathrm{em}$ suas atuações. E o gerencial, utiliza a assistência como base de suas ações e a educação como meio de conscientização, tanto para qualificação dos membros da equipe, quanto para orientações de clientes e familiares.

Convergindo o trabalho para o tema proposto, serão apresentados aspectos sobre o processo de trabalho gerencial na enfermagem.

\section{GERENCIAMENTO DA ENFERMAGEM}

Tratando desta temática, Marcon (2004), ressalta que ao reportar-se historicamente à prática da Enfermagem, o enfermeiro vem desempenhando, predominantemente, a função de gerente dos serviços de Enfermagem. A exemplo, há os que prestam cuidados diretos aos clientes, os que chefiam serviços de enfermagem e os que ministram aulas. Percebe-se que todos estão desenvolvendo continuamente atividades com características gerenciais, como: planejamento, organização, execução e avaliação.

A autora aponta que em muitas instituições, a estrutura diretiva de enfermagem é constituída de auxiliares, técnicos de enfermagem e enfermeiros. Este último com cargo assistencial e/ou gerencial. $O$ enfermeiro gerencial atua como líder desta equipe, responsável pela unidade e concomitantemetne intermediário entre direção e equipe de enfermagem.

Kurcgant (1991) em seu livro sobre Administração de Enfermagem, cita e explicita inúmeras atividades de enfermagem a serem realizadas pelo enfermeiro gerencial. Nesse momento a atenção será direcionada somente a atividade: Processo de Tomada de Decisão.

\section{PROCESSO DE TOMADA DE DECISÃO}

Em seus escritos, Chiavenato (1999, p.211) afirma que: "A teoria de decisão nasceu com

\footnotetext{
${ }^{2}$ Neste trabalho o termo Assistência é utilizado referindo-se às atividades
} de cuidado direto ao ser humano.
Herbert Simon, que a utilizou como base para explicar o comportamento humano nas organizações". O autor afirma que a teoria comportamental concebe a organização como um sistema permeado de decisões em que cada pessoa participa racional e conscientemente, da escolha, tomando decisões individuais. Define ainda, o processo decisório como a "análise de escolha, entre alternativas disponíveis, do curso de ação que a pessoa deverá seguir". Acrescentando que a decisão envolve critérios, conhecimentos, princípios e valores utilizados pelo tomador de decisão.

No contexto da Enfermagem, Perroca (1997) refere-se ao processo decisório como um dos assuntos centrais do contexto administrativo da profissão. A autora complementa que esta atividade necessita ser coerente com a filosofia do trabalho, com o estilo de liderança e a maneira como o profissional se compromete com a profissão e com seu grupo de trabalho. Alude ainda que o enfermeiro no cargo gerencial tem como prerrogativa a tomada de decisão, defrontandose com situações diversas que lhe exige conhecimentos, habilidades e atitudes coerentes e imparciais para uma conduta que venha ao encontro de valores pessoais e, ao mesmo tempo, atenda aos objetivos da organização.

$\mathrm{Na}$ mesma linha de pensamento, Chiavenato (1999, p.212), ressalta que:

Não é somente o administrador quem toma as decisões. Todas as pessoas dentro de uma organização, em todas as áreas de atividades, em todos os níveis hierárquicos e em todas as situações estão continuamente tomando decisões relacionadas ou não com o seu trabalho. A organização é um complexo sistema de decisões.

Percebeu-se que a autora que contextualiza o processo de tomada de decisão na enfermagem considera-o como prerrogativa do enfermeiro gerencial, aspecto interpretado como restrito. Já Chiavenatto, afirma que tal atividade é ação de todos funcionários inseridos em uma instituição.

Nesse sentido, percebe-se que em determinadas situações da vida do ser humano, pessoal ou profissional, o processo decisorial está envolvido. E na instituição hospitalar, o sistema de decisões é uma atividade de todos funcionários, 
em seu respectivo âmbito de atuação. O enfermeiro gerencial atua como mediador entre a equipe, a coordenação de enfermagem e a direção da instituição. Devido a isto, possui inúmeras e diversificadas situações que envolvem o processo decisório. Muitas dessas, envolvem diretamente seres humanos, trabalhadores, clientes ou familiares. Desse modo, àquelas requerem do enfermeiro conhecimentos em diversas áreas a fim de clarificar a problemática, discernir entre vários fatores e optar pela solução adequada, no momento.

No sentido de simplificar a complexidade do processo de tomada de decisão, Chiavenato (1999), apresenta os seguintes elementos que envolvem-no:

TOMADOR DE DECISÃO: é a pessoa que faz uma escolha ou opção entre várias alternativas de ação. É o agente que está frente a alguma situação.

OBJETIVOS: são as finalidades que o tomador de decisão pretende alcançar com suas ações.

PREFERÊNCIAS: são os critérios que o tomador de decisão usa para fazer sua escolha pessoal.

ESTRATÉGIA: é o curso de ação que o tomador de decisão escolhe para melhor atingir os objetivos. O curso de ação é o caminho escolhido. Depende dos recursos que dispõe e da maneira como percebe a situação.

SITUAÇÃO: são os aspectos do ambiente que envolve o tomador de decisão, muitos dos quais fora do seu controle, conhecimento ou compreensão e que afetam sua escolha.

RESULTADO: é a conseqüência ou resultante de uma dada estratégia.

A partir dos elementos do processo de decisão proposto por Chiavenato (1999), entendese que o tomador de decisão está inserido em um contexto singular, delineia objetivos a serem alcançados, possui conhecimentos e preferências pessoais, e ainda segue estratégias (cursos de ação), conforme a situação apresentada, para buscar a solução adequada para o momento.

O autor acima, em suas reflexões considera o processo decisorial complexo, dependente tanto das características pessoais do tomador de decisão, quanto da situação em que está envolvido e da maneira como este percebe a situação. Compreendendo a complexidade da temática e buscando clarificar os caminhos da problemática apresentada no atual estudo, delinou-se três modelos de etapas do processo de tomada de decisão. Ressalta-se que cada autor possui seu modelo próprio, sendo possivelmente adaptado e implementado conforme a necessidade da instituição.

Chiavenato (1999), estrutura seu modelo em sete etapas:

1)Percepção da situação que envolve algum problema;

2)Análise e definição do problema;

3)Definição de objetivos;

4)Procura de alternativas de solução ou de cursos de ação;

5)Avaliação e comparação dessas alternativas;

6)Escolha (seleção) da alternativa mais adequada ao alcance dos objetivos;

7)Implementação da alternativa escolhida.

O autor ressalta que cada etapa influencia as demais no decorrer do processo e, complementa que nem sempre tais etapas são seguidas. Diante do modelo enunciado, esclarecese que o autor apenas cita as etapas, não descrevendo-as, fato que pode gerar dúvidas em uma possível aplicação.

Com outro modelo de etapas do processo decisorial, Simon (1963, p.14), considera que o "processo de tomada de decisões compreende três fases principais: descobrir as ocasiões em que deve ser tomada; identificar os possíveis cursos de ação e decidir-se entre um deles."

O autor define a primeira fase como a Coleta de Informações, situação que necessita analisar o ambiente, procurando identificar as situações que exigem decisão. A segunda fase, chamada de Estruturação, tem a finalidade de criar, desenvolver e analisar possíveis cursos de ação. E a terceira, denominada Atividade de Escolha, tem o objetivo de escolher uma determinada linha de ação entre as disponíveis.

De maneira geral, o modelo do autor estrutura-se colocando que a fase de coleta de informações precede à de estruturação, e esta à de escolha. Entretanto ressalta-se que esse 'ciclo de fases', é mais complexo do que sugere a seqüência Simon (1963, p.16).

Ao finalizar a temática sobre etapas do processo de tomada de decisão (SIMON, 1963, p.18), enfatiza que: 
Cria-se o bom executivo quando o homem, possuidor de certos talentos naturais (inteligência e certa capacidade de exercer influência sobre seus semelhantes), à força de trabalho, estudo e amadurecimento, transforma essas qualidades em habilidades perfeitas. As habilidades exigidas nas atividades de coleta de informações, estruturação e escolha são tão assimiláveis e suscetíveis de treinamento quanto as habilidades exigidas para jogar golfe.

Em sintonia com o processo de tomada de decisões e suas etapas encontra-se Robbins (2002), que apresenta um modelo de etapas a serem seguidas descrevendo-as. O autor afirma que um modelo racional de tomada de decisão começa pela definição do problema. Este existindo quando há discrepância entre uma situação existente e outra desejada. Uma vez que o tomador de decisão tenha definido o problema, este precisa identificar os critérios que serão importantes para a solução. Nessa etapa, o responsável pela decisão estará determinando o que é relevante ao processo decisório. Neste passo é introduzido seus valores, crenças, e conhecimentos pessoais.

Dessa forma, a próxima etapa requer do tomador de decisão ponderação quanto aos critérios levantados/identificados, a fim de conferir prioridade na decisão. Em seguida, a outra etapa exige que este desenvolva alternativas. Geradas tais alternativas, torna-se necessário analisar cada uma. As vantagens e as desvantagens de cada alternativa tornam-se evidentes quando são comparadas em função dos critérios definidos na segunda e na terceira etapa.

A etapa final deste modelo requer um cálculo de decisão, exigindo que o tomador de decisão multiplique a eficácia esperada de cada escolha pelo peso de cada critério e pela pontuação de cada critério para cada alternativa. A alternativa com maior valor esperado torna-se, então, a escolha ótima.

O modelo acima descrito pode ser evidenciado em seis etapas, elaboradas segundo Robbins (2002, p.58).

1. Definir o problema;

2. Identificar critérios de decisão;

3. Pesar os critérios;

4. Gerar alternativas;

5. Classificar cada alternativa segundo cada critério;

\section{Calcular a decisão ótima.}

O autor complementa sua proposta de modelo inserindo pressupostos do modelo, no entanto esses não serão apresentados neste trabalho.

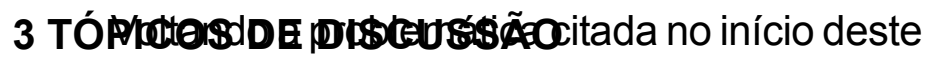
trabalho, que centralizou-se na ausência de modelos de etapas do processo decisório na enfermagem, buscou-se alguns autores que apresentam modelos de etapas do processo de tomada de decisão. Os autores referenciados da área da administração foram: Chiavenato (1999), Simon (1963) e Robbins (2002).

Analisando o modelo proposto por Chiavenato (1999), demonstra-se que o processo decisorial é prescrito em sete etapas, abordando passos a serem seguidos diante de um problema para chegar a uma resolução. No entanto, observase que o autor apenas elenca as etapas em seu modelo, sem descrevê-las, cabendo ao profissional que o utilize ter que desenvolver suas próprias interpretações. Acredita-se que tal aspecto pode gerar dúvidas quanto a sua adequação para a aplicabilidade.

O modelo proposto por Simon (1963), sintetiza o processo de tomada de decisão em três etapas e descreve-as brevemente. Considerou-se tal modelo sucinto para fundamentar uma decisão, visto ser um processo complexo que requer competências diversas para buscar uma solução adequada que satisfaça a todos inseridos no contexto.

O modelo proposto por Robbins (2002), apresenta seis etapas, havendo descrição e pressupostos do modelo. Este aborda questões como os elementos que o tomador de decisão utiliza e em que etapa tal atitude pode ser observada. Indica-se a utilização deste modelo, pelo fato de apresentar as etapas descritas, não resultando em limitações quanto ao entendimento e podendo ser adaptado à Enfermagem.

\section{CONSIDERAÇÕES FINAIS}

Conforme visto, o processo de trabalho da enfermagem se baseia em três formas de atuar para obter o produto final da enfermagem, cuja importância entre as três é igualitária e 
desenvolvem-se concomitantemente para um único resultado. Focando o olhar sobre processo de trabalho gerencial, pode-se perceber que este é encontrado em todas as atividades de enfermagem.

Direcionando a atenção para o processo de tomada de decisão durante o processo de trabalho gerencial, principalmente na adaptação de modelos de etapas para a Enfermagem, considerou-se que o modelo proposto por Chiavenato (1999) pode remeter a dúvidas ao profissional que for utilizá-lo, pelo fato de não descrever suas etapas, causando certa insegurança no indivíduo, de modo que as interpretações serão desenvolvidas individualmente.

O modelo proposto por Simon (1963), parece ser sucinto para aplicar em uma atividade tão complexa como o processo de tomada de decisão. Enquanto que o modelo proposto por Robbins (2002), demonstrou-se flexível e compreensível para uma posterior adaptação e implementação no processo de trabalho gerencial da enfermagem. Complementado, coloca-se que tal tema não se esgota nesses três autores.

O fato de desenvolver um modelo de etapas de processo decisorial nas atividades gerenciais da enfermagem, visa contribuir para guiar a tomada de decisões quanto ao início, meio e fim. Tornandoa menos 'imediatista' e mais reflexiva, resultando em ações benéficas, justas, imparciais, íntegras, enfim, mais adequadas, e de confiabilidade pelos envolvidos no processo de trabalho.

Ao finalizar, considera-se que um modelo de etapas para o processo de tomada de decisão pretende clarificar as etapas do processo, analisando criticamente as circunstâncias concretas e servir como guia para solução de problemas.

ABSTRACT: This article is about a reflection on the Nursing while practical professional, showing its process of work in three great areas, defined as some authors, as Taking Care of, Educating and Managing. With emphasis on this last one, the objective of this study was to argue the viability of models of directed stages of the decisorial process for application in the Nursing. To achieve this proposal there is a reference to the three authors of the area of administration, who present proper models. After the understanding and argument of the theoretical references, it was considered that not all the models can easily be understood and applied.

KEY WORDS: Management in nursing; Power to decide process; Practical professional.

\section{REFERÊNCIAS}

CHIAVENATO, I. Teoria Geral da Administração. 6. ed. Rio de Janeiro: Campus, 1999. 2 v.

KURCGANT, P. (Coord.). Administração em Enfermagem. São Paulo: Pedagógica e Universitária LTDA, 1991.

LEOPARDI, M. T; GELBCKE, F. L; RAMOS, F .R .S. Cuidado: objeto de trabalho ou objeto epistemológico da enfermagem? Revista Texto \& Contexto, Florianópolis, vol. 10, n. 1, p.32-49, jan./ abr. 2001.

MARCON, P. M. Proposta de um instrumento de auto-análise crítica para o Processo de Trabalho Gerencial da Enfermagem, fundamentado nos princípios da Bioética. 2004. 67f. Monografia (Especialização em Gestão dos Serviços de Enfermagem), - Faculdade de Enfermagem, Universidade Federal de Santa Catarina, Florianópolis, 2004.

MESQUITA, M. P. R. L. A Dimensão Gerencial da Identidade profissional da (o) Enfermeira (o) na percepção da equipe de enfermagem: uma perspectiva de construção coletiva. 2002. $147 \mathrm{f}$. Dissertação (Mestrado em Enfermagem) Faculdade de Enfermagem, Universidade Federal de Santa Catarina, Florianópolis, 2004.

PERROCA, M. G. Valores que norteiam o processo de tomada de decisão da enfermeira. Rev. Esc. de Enf. USP, São Paulo, v.31, n.2, p. 206-18, ago. 1997

ROBBINS, S. P. Administração: mudanças e perspectivas. Tradução de Cid Knipel Moreira. São Paulo: Saraiva, 2002.

RODRIGUES, E. et al. O Processo de Trabalho do Enfermeiro na Equipe de Saúde da Família: uma proposta enfocando a capacitação dos 
agentes comunitários de saúde. 2003. $185 f$. Trabalho de Conclusão de Curso (Graduação em Enfermagem) - Faculdade de Enfermagem, Universidade Federal de Santa Catarina, Florianópolis, 2003.

SIMON, H. A. A capacidade de decisão e liderança. Rio de Janeiro: Fundo de Cultura, 1963.

ENDEREÇO DAS AUTORAS:

Rua Cônego Bernardo, 100 - ap. 303

Florianípolis/SC

88020-570

patriciammarcon@terra.com.br 